\title{
Psychiatric Symptoms During the Post-partum Period as Related to Use of Oral Contraceptives
}

\author{
A. NILSSON,* M.B. ; P.-E. ALMGREN, $†$ F.K.
}

Brit. med. F., 1968, 2, 453-455

In a retrospective study of the psychiatric changes associated with the use of an oral contraceptive (Nilsson et al., 1967) an increase of psychiatric symptoms was reported in $17 \%$ of the patients. The symptomatology waš mainly of a neurasthenic and depressive nature; no marked increase in anxiety symptoms could be established. Analysis of the material showed that an increase of psychiatric symptoms was related to earlier cessation of treatment, a previous history of psychiatric symptoms or insufficiency, especially in previous pregnancies, impaired sexual adaptation (essentially decreased libido), and weight increase. An association between increase in psychiatric symptoms and the use of oral contraceptives has also been reported by others (Hauser and Schubiger, 1965 ; Kane et al., 1967 ; Nilsson and Sölvell, 1967).

\section{The Study}

This study is intended to give further information on these matters. Two groups of women, one with oral contraceptive administration and one with more conventional contraceptive methods, are compared with respect to certain psychiatric and other variables.

\section{Method and Results}

The present report is part of a comprehensive study of the psychiatric and social adaptation during pregnancy and the post-partum period. The material, comprising 165 women, is entirely representative of the women confined at the University Hospital of Lund. The patients underwent thorough psychiatric and psychological examination-once early during pregnancy and once six to seven months post partum-the examinations being performed by the two of us. The conditions during the latter part of the pregnancy-that is, from the first examination up to partus-were explored in an interview on the second day after delivery.

Owing to the explorative nature of the study we had to take into account a large number of variables possibly relevant to adaptation during pregnancy and the post-partum period. In addition to purely psychiatric conditions, the interview dealt with gynaecological and other somatic factors, sexual habits and adaptation, information on contraceptive practice and social conditions, hereditary factors, etc. The investigations were performed according to a pre-established scheme and the data obtained were consecutively recorded and classified on punch cards.

Since the contraceptive technique used was also recorded at the third interview it was possible to compare 54 women prescribed an oral contraceptive in the post-partum period ( $P$ group) with 104 women who used a more conventional contraceptive technique (C group). Seven women who used oral contraception only before pregnancy were excluded. The women in the $\mathbf{P}$ group had been using oral contraceptives for

- Psychiatrist.

† Assistant Psychologist.

Department of Psychiatry I, University of Lund, Sweden. The preparations were Anovlar mite, Conluten, Lyndiol mite, and
Ovulen. two to four months at the time of the third examination. ${ }^{1}$ The statistical treatment was performed by $\chi^{2}$ technique applied to fourfold or sixfold tables.

Table I shows a comparison between the two groups at the first and the second examination, from which it is clear that the groups do not differ with respect to the variables treated.

TABLB I.- $\chi^{2}$ Values for Differences Between the Two Groups with Different Contraceptive Methods with Regard to Conditions Before and During Pregnancy

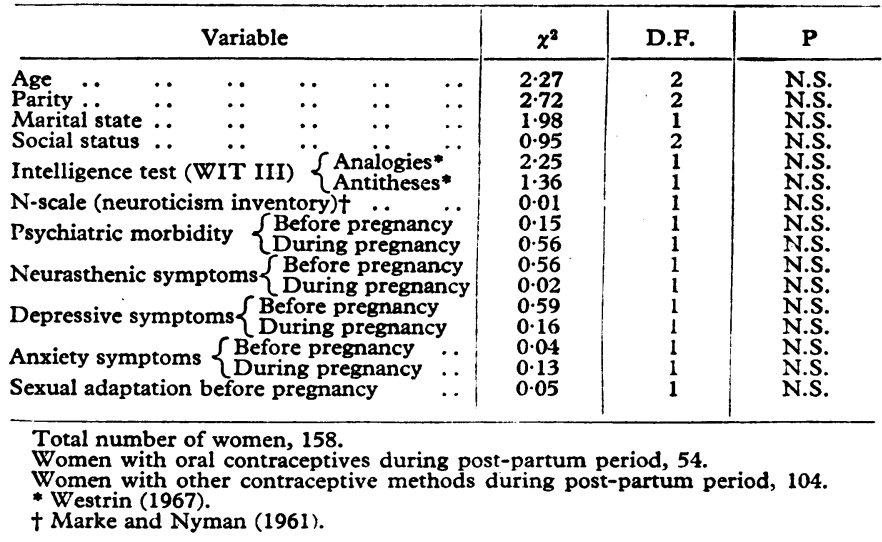

The psychiatric symptoms were established on the basis of subjective reports given by the women at the different examinations. The neurasthenic syndrome included the following symptoms: increased fatigability, increased emotional lability, and irritability. The depression symptoms were: feeling of depression, feeling of inferiority, difficulty in starting work, worry about the future, and sleep disturbance of a depressive nature. The anxiety symptoms were: attacks of fear, palpitations, globus, breathing difficulties, tension, and anxiety. Two or more symptoms in any one of the symptom groups was taken as indicative of the existence of the syndrome.

As a measure of the psychiatric morbidity the total number of psychiatric symptoms (maximum number of symptoms, 42) was calculated, some consideration being paid to the intensity of the symptoms. Women who reported psychiatric symptoms or an insufficiency period were assigned to a high-scoring group. The remainder, a low-scoring group, comprised women with no symptoms. Naturally the criteria of classification were identical for the periods before, during, and after pregnancy.

Table II presents comparisons between the groups in the post-partum period regarding individual psychiatric symptoms,

TABLE II.- $\chi^{2}$ Values for Differences Between the Two Groups with Different Contraceptive Methods with Regard to Conditions During the Post-partum Period

\begin{tabular}{|c|c|c|c|c|c|}
\hline \multicolumn{3}{|l|}{ Variable } & $x^{2}$ & D.F. & $\mathbf{P}$ \\
\hline $\begin{array}{l}\text { Psychiatric morbidity } \\
\text { Neurasthenic symptoms } \\
\text { Depressive symptoms }\end{array}$ & $\begin{array}{l}\cdots \\
\cdots \\
\cdots \\
\cdots\end{array}$ & $\begin{array}{l}\cdots \\
\cdots \\
\cdots \\
\cdots\end{array}$ & $\begin{array}{l}5 \cdot 46 \\
5 \cdot 18 \\
3 \cdot 80 \\
0 \cdot 02 \\
3 \cdot 83 \\
3 \cdot 15 \\
9 \cdot 86\end{array}$ & $\begin{array}{l}1 \\
1 \\
2 \\
1 \\
1\end{array}$ & $\begin{array}{l}<0.01^{*} \\
<0.05^{*} \\
<0.05^{*} \\
\text { N.S. } \\
\text { N.S.* } \\
\text { N.S. } \\
<0.005^{*}\end{array}$ \\
\hline
\end{tabular}

* Significance tests are one-tailed in view of the hypotheses suggested in a previous nulblication (Nilsson et al., 1967). 
TABle III.-Distributions of the $C$ and $P$ Groups on Psychiatric Variables Before, During, and After Pregnancy

\begin{tabular}{|c|c|c|c|c|c|c|c|c|c|c|c|c|c|c|c|c|c|c|}
\hline & & & & & & & \multicolumn{4}{|c|}{ Before Pregnancy } & \multicolumn{4}{|c|}{ During Pregnancy } & \multicolumn{4}{|c|}{ Post-partum Period } \\
\hline & \multicolumn{5}{|c|}{ Variables } & & \multicolumn{2}{|c|}{ C Group } & \multicolumn{2}{|c|}{ P Group } & \multicolumn{2}{|c|}{ ᄃ Group } & \multicolumn{2}{|c|}{ P Group } & \multicolumn{2}{|c|}{ C Group } & \multicolumn{2}{|c|}{ P Group } \\
\hline & & & & & & & No. & $\%$ & No. & $\%$ & No. & $\%$ & No. & $\%$ & No. & $\%$ & No. & $\%$ \\
\hline $\begin{array}{l}\text { No psychiat } \\
\text { Slight psych } \\
\text { Slight to mo } \\
\text { Clear psych } \\
\end{array}$ & $\begin{array}{l}\text { c syn } \\
\text { ate in } \\
\text { insu }\end{array}$ & $\begin{array}{l}\text { ms at a } \\
\text { ptoms } \\
\text { ufficien } \\
\text { ficiency }\end{array}$ & $\begin{array}{l}\ddot{y} \mathrm{p} \\
\text { peri }\end{array}$ & $\begin{array}{l}\cdots \\
\text { od or } p \\
\text { or peri }\end{array}$ & $\begin{array}{l}\ldots \\
\text { eriods } \\
\text { ods }\end{array}$ & $\begin{array}{l}. . \\
\because \\
\because\end{array}$ & $\begin{array}{l}41 \\
25 \\
26 \\
12 \\
\end{array}$ & $\begin{array}{l}39.4 \\
24.0 \\
25.0 \\
11.6\end{array}$ & $\begin{array}{r}23 \\
16 \\
8 \\
7 \\
\end{array}$ & $\begin{array}{l}42 \cdot 6 \\
29.6 \\
14.8 \\
13.0 \\
\end{array}$ & $\begin{array}{l}18 \\
38 \\
26 \\
22 \\
\end{array}$ & $\begin{array}{l}17 \cdot 3 \\
36 \cdot 5 \\
25 \cdot 0 \\
21 \cdot 2\end{array}$ & $\begin{array}{l}12 \\
17 \\
12 \\
13\end{array}$ & $\begin{array}{l}22 \cdot 2 \\
31 \cdot 5 \\
22 \cdot 2 \\
24 \cdot 1\end{array}$ & $\begin{array}{l}38 \\
27 \\
24 \\
15\end{array}$ & $\begin{array}{l}36 \cdot 5 \\
26 \cdot 0 \\
23.1 \\
14 \cdot 4 \\
\end{array}$ & $\begin{array}{l}10 \\
17 \\
16 \\
11 \\
\end{array}$ & $\begin{array}{l}18 \cdot 5 \\
31 \cdot 5 \\
29 \cdot 6 \\
20.4 \\
\end{array}$ \\
\hline Total & .. & $\ldots$ & .. & .. & $\ldots$ & $\ldots$ & 104 & & 54 & & 104 & & 54 & & 104 & & 54 & \\
\hline \multicolumn{5}{|c|}{$\begin{array}{l}\text { No neurasthenic symptoms }(0-1 \text { symptom) } \\
\text { Neurasthenic symptoms }(2+) \ldots \quad \ldots \\
\end{array}$} & 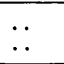 & $\therefore$ & $\begin{array}{l}86 \\
18\end{array}$ & $\begin{array}{l}82.7 \\
17.3 \\
\end{array}$ & $\begin{array}{l}42 \\
12\end{array}$ & $\begin{array}{l}77 \cdot 8 \\
22 \cdot 2\end{array}$ & $\begin{array}{l}72 \\
32\end{array}$ & $\begin{array}{l}69 \cdot 2 \\
30 \cdot 8\end{array}$ & $\begin{array}{l}38 \\
16\end{array}$ & $\begin{array}{l}70 \cdot 4 \\
29.6\end{array}$ & $\begin{array}{l}73 \\
31\end{array}$ & $\begin{array}{l}70 \cdot 2 \\
29.8\end{array}$ & $\begin{array}{l}28 \\
26\end{array}$ & $\begin{array}{l}51.9 \\
48.1\end{array}$ \\
\hline Total & .. & .. & .. &.. & $\ldots$ & $\ldots$ & 104 & & 54 & & 104 & & 54 & & 104 & & 54 & \\
\hline \multicolumn{3}{|c|}{$\begin{array}{l}\begin{array}{l}\text { No depressive symptoms }(0-1) \\
\text { Depressive symptoms }(2+)\end{array} \\
\end{array}$} & $\ldots$ & $\because$. &.. & $\because$ & $\begin{array}{l}75 \\
29\end{array}$ & $\begin{array}{l}72.1 \\
27.9\end{array}$ & $\begin{array}{l}42 \\
12\end{array}$ & $\begin{array}{l}77.8 \\
22 \cdot 2\end{array}$ & $\begin{array}{l}65 \\
39\end{array}$ & $\begin{array}{l}62.5 \\
37.5\end{array}$ & $\begin{array}{l}32 \\
22\end{array}$ & $\begin{array}{l}59 \cdot 3 \\
40 \cdot 7\end{array}$ & $\begin{array}{l}79 \\
25\end{array}$ & $\begin{array}{l}76.0 \\
24.0\end{array}$ & $\begin{array}{l}33 \\
21\end{array}$ & $\begin{array}{l}61 \cdot 1 \cdot 1 \\
38 \cdot 9\end{array}$ \\
\hline Total &.. & .. & .. & .. & .. & .. & 104 & & 54 & & 104 & & 54 & & 104 & & 54 & \\
\hline \multicolumn{3}{|c|}{$\begin{array}{l}\text { No anxiety symptoms }(0-1) \\
\text { Anxiety symptoms }(2+) . .\end{array}$} & $\because$. & $\because$. & $\because$. & $\because$ & $\begin{array}{l}69 \\
35\end{array}$ & $\begin{array}{l}66.3 \\
33.7\end{array}$ & $\begin{array}{l}35 \\
19\end{array}$ & $\begin{array}{l}64 \cdot 8 \\
35 \cdot 2\end{array}$ & $\begin{array}{l}77 \\
27\end{array}$ & $\begin{array}{l}74 \cdot 0 \\
26 \cdot 0\end{array}$ & $\begin{array}{l}41 \\
13\end{array}$ & $\begin{array}{r}75 \cdot 9 \\
\cdot 24 \cdot 1\end{array}$ & $\begin{array}{l}78 \\
26\end{array}$ & $\begin{array}{l}75 \cdot 0 \\
25 \cdot 0\end{array}$ & $\begin{array}{l}40 \\
14\end{array}$ & $\begin{array}{l}74 \cdot 1 \\
25 \cdot 9\end{array}$ \\
\hline Total &.. & .. & $\ldots$ & .. & .. & $\ldots$ & 104 & & 54 & & 104 & & 54 & & 104 & & 54 & \\
\hline
\end{tabular}

an estimate of the psychiatric morbidity, sexual adaptation, and weight changes.

During the post-partum period there is a significant overrepresentation of the total number of psychiatric symptoms in the group using oral contraceptives. The occurrence of appreciable symptoms and clear psychiatric insufficiency is $12.5 \%$ greater in this group than in the group using more conventional contraceptive techniques (Table III). Neither for neurasthenic symptoms nor for depression were any differences found between the two groups before or during pregnancy, but in the post-partum period both types of symptoms occurred to a significantly greater extent in women using oral contraception (Table III). In both groups there is an increase in the number of women with such symptoms as compared with the situation before pregnancy, which may be ascribed to the fact that psychiatric symptoms are generally more common during the puerperium and post-partum period. The differences between the groups cannot, however, be explained in this way. The overrepresentation of women with neurasthenic and depressive symptoms in the oral contraception group is, respectively, 18.3 and $15.3 \%$. There were no differences between the two groups regarding symptoms of an anxietytension nature, either before parturition or during the postpartum period (Table III).

There were no differences between the groups in sexual adaptation before or during pregnancy. During the postpartum period no significant differences were found in improved, unchanged, or impaired adaptation, but there was a clear tendency for greater fluctuation towards both improve- ment and impairment in the group with oral contraception (Fig. 1).

At the first examination every patient reported her normal weight during the year preceding pregnancy, and at the examination six to seven months after delivery all patients were weighed. The weight changes recorded are shown in Fig. 2. Weight gain was significantly greater in the group with oral contraception as regards both the total incidence of weight gain and weight gain greater than $5 \mathrm{~kg}$. (Table II).

\section{Discussion}

Within the present study, which is prospective and has been designed principally to establish the psychiatric and social adaptation associated with delivery, it has been possible to compare a group of women who used oral contraception in the post-partum period with a group who used conventional contraceptive techniques. Exploration of the patients' psychiatric condition comprised the most important part of each interview and was always taken first, whereas information on sexual adaptation and contraceptive technique was obtained at the end of the interviews. At the time of investigation neither the patients nor the investigators were aware that the relation between use of oral contraceptives and psychiatric symptoms was later to be subject to special study. Only two women spontaneously reported an association of psychiatric symptoms with the use of contraceptive tablets. The majority did not relate their symptoms to the tablets at all, but rather to their post-partum condition. Thus, in our view, an important bias factor has been eliminated to a great extent-namely, any expectation by the patient, the investigator, or both, that the effects of the oral medication would lead to differences of the type observed.

It is not possible to establish with certainty the reasons why some women were prescribed contraceptive tablets while others did not choose this technique. There were no differences between the two groups regarding background variables or social and psychological factors before or during pregnancy. It is, however, probable that those who received oral contraceptives were more anxious to use a safe method. This is reflected indirectly by the fact that they, to a greater extent than the others, replied negatively to a question on whether they desired a further pregnancy; this relation was not, however, statistically significant. Fig. 1.--Sexual adaptation during post-partum period. Fig. 2.-Weight changes during obser-
vation period. 
A minority of those not using oral contraception may not have been sufficiently gifted to employ such medication without difficulty, but no marked differences were found in median intelligence scores between the two groups. The possibility that the group of women who received oral contraceptives during the post-partum period chose this method just because they, to a greater extent than the others, had experienced increased psychiatric symptoms during the early post-partum period is judged to be unlikely. The only factor which seems able to account for the differences found in psychiatric symptoms, especially neurasthenic and depressive ones, and in weight gain, is that one of the groups used oral contraceptives while the other did not. Unfortunately, the material is not sufficiently large to enable a closer analysis to be made within the oral contraception group of what further factors lead to an impairment in some women. No increase of anxiety-tension symptoms was found in the material, but this does not necessarily imply that such symptoms did not increase in certain cases. On the contrary, it is possible that such an increase occurred but was balanced out by a group of women who had anxiety symptoms before medication which decreased owing to the greater security provided by the contraceptive.

The results obtained suggest that there is a causal connexion between use of oral contraceptives and an increase of psychiatric symptoms in a number of women. Since the pattern of symptoms is selective, comprising mainly those of a neurasthenic or depressive type, and since no differences in total psychiatric morbidity existed in the material before or during pregnancy, the side-effects found may to a large extent be ascribed $t c$ hormonal factors. The results of this investigation cover only the first four months of medication. We are unable to judge whether or not the observed changes persist over a longer period of treatment. The results from other studies (Nilsson et al., 1967 ; Nilsson and Sölvell, 1967) do, however, suggest that psychiatric symptoms occur primarily in the initial stages of medication. It is difficult to explain why the frequency of side-effects seems to decrease with increasing observation time. One important factor is probably that a large number of women who experience such symptoms discontinue treatment at an early stage and have therefore dropped out of later investigations.

\section{Summary}

In a prospective psychiatric and psychological investigation of 165 women during pregnancy and the post-partum period it has been possible to compare 54 women who were prescribed oral contraceptives during the post-partum period with 104 women who used other contraceptive methods. There were no differences between the two groups in respect of psychiatric symptoms and psychological or social factors before medication -that is, before and during pregnancy. During the postpartum period a significantly higher frequency of psychiatric symptoms was found in the oral contraceptive group as regards both the total number of psychiatric symptoms and individual symptoms of a neurasthenic and depressive nature. These side-effects may be causally related to the tablet medication and can presumably be ascribed to hormonal factors.

This study is part of an investigation supported by grants from the Medical Research Council of Sweden.

\section{REFERENCES}

Hauser, G. A., and Schubiger, V. (1965). Arch. Gynäk., 202, 175.

Kane, F. J., jun., Daly, R. J., Ewing, J. A., and Keeler, M. H. (1967) Brit. F. Psychiat., 113, 265.

Marke, S., and Nyman, G. E. (1961). Socialmed. T., 38, 315.

Nilsson, Ä., Jacobson, L., and Ingemanson, C.-A. (1967). Acta obstet. gynec. scand., 46, 537.

Nilsson, L., and Sölvell, L. (1967). Acta obstet. gynec. scand., 46, Suppl. No. 8 .

Westrin, P. A. (1967). WIT III. Manual. Stockholm.

\title{
Infective Endocarditis in Three Patients with Hypertrophic Obstructive Cardiomyopathy
}

\author{
R. J. VECHT,* M.B., CH.B. ; C. M. OAKLEY, $\dagger$ M.D., M.R.C.P.
}

Brit. med. F., 1968, 2, $455-459$

Infective endocarditis is a little-known complication of hypertrophic obstructive cardiomyopathy, though it may not be uncommon.

Boiteau and Allenstein (1961) described two cases, one of which had evidence of healed endocarditis on the mitral valve at necropsy. Soulie et al. (1962) and Linhart and Taylor (1966) reported two further cases. Franks and Braunwald (1968) have recorded three other well-documented cases. In one of these the aortic valve was seen at operation to have been the site of the infection. The same authors describe one probable and two possible further cases of endocarditis in patients with this condition.

To these cases we add three of our own seen at Hammersmith Hospital between 1959 and 1967.

Hypertrophic obstructive cardiomyopathy is now a wellrecognized clinical entity. As it is known to be a disorder of the myocardium the possible development of infective endo-

* House-physician, Hammersmith Hospital, London W.12.

+ Consultant Physician and Lecturer in Medicine, Department of Medicine (Clinical Cardiology), Royal Postgraduate Medical School, Hammersmith Hospital, London W.12. Supported by the British Heart Foundation. carditis may not readily be considered, and no such cases have yet been recorded in the British literature. Our purpose is to emphasize the risk of this complication, to discuss the reasons for the susceptibility of patients with this form of cardiomyopathy to infective endocarditis, and to stress the necessity for preventive measures.

\section{Case 1}

The patient was 39 years old when he first presented in 1964 He was a battery manufacturer who for the previous five years had suffered from angina of effort and dyspnoea on exertion.

He had florid clinical signs of hypertrophic obstructive cardiomyopathy with jerky pulses, a double apical impulse, and a lateonset systolic murmur at the apex, which radiated to the axilla and to the left sternal border. The blood pressure was 110/60. His electrocardiogram showed left ventricular hypertrophy with an intraventricular conduction defect (Fig. 1), and on chest radiography the left ventricle was seen to be prominent (Fig. 2).

Left ventricular catheterization showed an intraventricular gradient of $127 \mathrm{~mm}$. Hg. Furthermore, on left ventricular angiography the left ventricle had the typical appearance of severe hypertrophic obstructive cardiomyopathy with over-complete systolic emptying, a 